\title{
Conformers of $\beta$-aminoisobutyric acid probed by jet-cooled microwave and matrix isolation infrared spectroscopic techniques
}

N. Kuş, A. Sharma, I. Peña, M. C. Bermúdez, C. Cabezas, J. L. Alonso, and R. Fausto

Citation: The Journal of Chemical Physics 138, 144305 (2013); doi: 10.1063/1.4799456

View online: https://doi.org/10.1063/1.4799456

View Table of Contents: http://aip.scitation.org/toc/jcp/138/14

Published by the American Institute of Physics

\section{Articles you may be interested in}

Relaxation of conformers and isomers in seeded supersonic jets of inert gases

The Journal of Chemical Physics 93, 3142 (1990); 10.1063/1.458848

Rotational spectrum of tryptophan

The Journal of Chemical Physics 140, 204308 (2014); 10.1063/1.4876001

Conformers, infrared spectrum, UV-induced photochemistry, and near-IR-induced generation of two rare conformers of matrix-isolated phenylglycine

The Journal of Chemical Physics 141, 154306 (2014); 10.1063/1.4897526

Near-IR laser generation of a high-energy conformer of L-alanine and the mechanism of its decay in a lowtemperature nitrogen matrix

The Journal of Chemical Physics 138, 125101 (2013); 10.1063/1.4795823

Effect of $S$ and $O$ on the growth of chemical-vapor deposition diamond (100) surfaces

The Journal of Chemical Physics 115, 5284 (2001); 10.1063/1.1396816

Simple models for heterogeneous catalysis: Phase transition-like behavior in nonequilibrium systems

The Journal of Chemical Physics 87, 731 (1987); 10.1063/1.453570

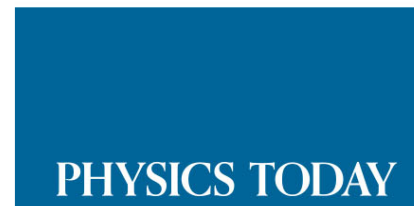

WHITEPAPERS
ADVANCED LIGHT CURE ADHESIVES

READ NOW

Take a closer look at what these environmentally friendly adhesive systems can do
PRESENTED BY

8 MASTERBOND' 


\title{
Conformers of $\beta$-aminoisobutyric acid probed by jet-cooled microwave and matrix isolation infrared spectroscopic techniques
}

\author{
N. Kuş, ${ }^{1,2, a)}$ A. Sharma, ${ }^{1, b)}$ I. Peña, ${ }^{3, c)}$ M. C. Bermúdez, ${ }^{3, d)}$ C. Cabezas, ${ }^{3, e)}$ J. L. Alonso, ${ }^{3, f)}$ \\ and R. Fausto ${ }^{1, g)}$ \\ ${ }^{1}$ Department of Chemistry, University of Coimbra, P-3004-535 Coimbra, Portugal \\ ${ }^{2}$ Department of Physics, Anadolu University, 26470 Eskişehir, Turkey \\ ${ }^{3}$ Grupo de Espectroscopia Molecular (GEM), Unidad Asociada CSIC, Edificio Quifima, Laboratorios de \\ Espectroscopia y Bioespectroscopia, Universidad de Valladolid, 47005 Valladolid, Spain
}

(Received 23 January 2013; accepted 20 March 2013; published online 12 April 2013)

\begin{abstract}
$\beta$-aminoisobutyric acid (BAIBA) has been studied in isolation conditions: in the gas phase and trapped into a cryogenic $\mathrm{N}_{2}$ matrix. A solid sample of the compound was vaporized by laser ablation and investigated through their rotational spectra in a supersonic expansion using two different spectroscopic techniques: broadband chirped pulse Fourier transform microwave spectroscopy and conventional molecular beam Fourier transform microwave spectroscopy. Four conformers with structures of two types could be successfully identified by comparison of the experimental rotational and ${ }^{14} \mathrm{~N}$ nuclear quadruple coupling constants with those predicted theoretically: type $\mathbf{A}$, bearing an $\mathrm{OH} \cdots \mathrm{N}$ intramolecular hydrogen bond and its carboxylic group in the trans geometry $(\mathrm{H}-\mathrm{O}-\mathrm{C}=\mathrm{O}$ dihedral $\sim 180^{\circ}$ ), and type $\mathbf{B}$, having an $\mathrm{NH} \cdots \mathrm{O}$ bond and the cis arrangement of the carboxylic group. These two types of conformers could also be trapped from the gas phase into a cryogenic $\mathrm{N}_{2}$ matrix and probed by Fourier transform infrared (IR) spectroscopy. In situ irradiation of BAIBA isolated in $\mathrm{N}_{2}$ matrix of type $\mathbf{B}$ conformers using near-IR radiation tuned at the frequency of the $\mathrm{O}-\mathrm{H}$ stretching 1 st overtone $\left(\sim 6930 \mathrm{~cm}^{-1}\right)$ of these forms allowed to selectively convert them into type A conformers and into a new type of conformers of higher energy (type $\mathbf{D}$ ) bearing an $\mathrm{NH} \cdots \mathrm{O}=\mathrm{C}$ bond and a $\mathrm{O}-\mathrm{H}$ "free" trans carboxylic group. (C) 2013 American Institute of Physics. [http://dx.doi.org/10.1063/1.4799456]
\end{abstract}

\section{INTRODUCTION}

$\beta$-Aminoisobutyric acid (BAIBA) is a non-proteinogenic amino acid, whose occurrence in nature was established as early as in $1951 .{ }^{1}$ It is a thymine and antiretroviral thymineanalogues zidovudine (AZT) and stavudine (d4T) catabolite, which has been found to increase fatty acid oxidation in liver and reduce the gain of body fat mass in mice. ${ }^{2,3}$ BAIBA is also a partial agonist at the glycine receptor (GlyR), competitively inhibiting glycine responses at low concentration. ${ }^{4}$ It has been recently found that a common binding site for all amino acid agonists and antagonists exists in GlyR, at which the functional consequences of binding depend on the particular conformation adopted by the amino acid ligand within the binding pocket. ${ }^{4}$

From the conformational point of view, BAIBA is extremely flexible, since it possesses four internal rotation axes that can give rise to conformational isomerism (Scheme 1). This characteristic can be relevant in determining physical and chemical properties, as well as the bioactivity of BAIBA.

\footnotetext{
a)E-mail: nkus@ anadolu.edu.tr. Telephone: +90-53-22086547.

b) E-mail: dr.archnasharma@ gmail.com. Telephone: +351-239-854483. Fax: +351 +239-827703

c) E-mail: ipencal@qf.uva.es. Telephone: +34-983-186348.

d)E-mail: cbermu@qf.uva.es. Telephone: +34-983-186348.

e) E-mail: ccabezas@qf.uva.es. Telephone: +34-983-186348.

f)E-mail: jlalonso@qf.uva.es. Telephone: +34-983-186348.

g) Author to whom correspondence should be addressed. Electronic mail: rfausto@ci.uc.pt. Telephone: +351-239-854483. Fax: +351-239-827703.
}

Nevertheless, no conformational studies on BAIBA have been reported hitherto. In the present study, we focus on the identification of various conformers of BAIBA using different experimental spectroscopic techniques, supported by theoretical methods.

Microwave spectroscopy is a well-known technique for the identification and study of conformations of molecules by virtue of their rotational spectra. The development of Fourier transform microwave techniques in a molecular beam and laser ablation methods have made feasible to know in detail the shape of high melting point biomolecules. In this way, laser ablation molecular beam Fourier transform microwave spectroscopy (LA-MB-FTMW) has been proved to be particularly adequate to study amino acids,,${ }^{5-12}$ dipeptides, ${ }^{13} \mathrm{nu}-$ cleic acid bases, ${ }^{14-16}$ neurotransmitters, ${ }^{17-20}$ and drugs. ${ }^{21,22}$ This field of research has been recently revitalized with the new setup of a broadband microwave spectrometer for chirped pulse Fourier transform microwave spectroscopy ${ }^{23,24}$ with a

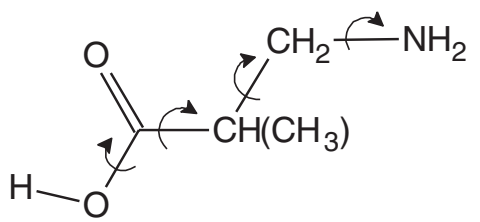

SCHEME 1. Schematic representation of BAIBA with indication of its 4 internal torsional degrees of freedom which can give rise to conformational isomers. 
laser ablation source, ${ }^{25-27}$ which allows the rapid acquisition of the rotational spectra in a wide frequency range, making more efficient the search of different conformers in the jet.

On the other hand, the matrix isolation IR spectroscopic technique is also a powerful tool to probe molecular conformers. Unless the barriers for conformational isomerization are very low (a few $\mathrm{kJ} \mathrm{mol}^{-1}$ ), in a matrix isolation experiment the conformational equilibrium present in the vapor of the compound under study prior to deposition of the matrix can be successfully trapped into the solid cryogenic sample. It is then in general easier to identify and characterize structurally the different conformers initially present in the gas phase equilibrium using infrared spectroscopy probing. In a cryogenic matrix, vibrational spectra show a higher resolution compared to other, more conventional, sampling techniques, and the spectra are very much simplified due to the fact that the trapped molecules are not interacting to each other (once the concentration of the matrix is low) and do not rotate nor diffuse. Hence, subtle spectroscopic differences due to conformational changes can be clearly noticed, and the identity of the various conformers present in the matrix established with certainty. ${ }^{28-34}$ On the other hand, when the energy barriers separating different conformers are only of a few kJ $\mathrm{mol}^{-1}$, conformational cooling can take place during matrix deposition leading to conversion of higher energy conformers into lower energy forms. In this case, the relative populations of the conformers trapped in the cryogenic matrix may differ substantially from those existing in the gas phase prior to deposition. ${ }^{34-37}$ The observation of conformational cooling thus provide important clues regarding the conformational dynamics, size of the internal barriers of rotation and relative order of stability of the conformers. ${ }^{34-37}$ Furthermore, it is in general possible to induce conversions between the matrixisolated conformers, either by annealing the matrix at a temperature above that at which it was deposited (favoring again lower energy conformers), or by in situ irradiation of the matrix with IR or UV/visible light. ${ }^{34-43}$

In the present work, we used jet cooled supersonic expansions coupled with Fourier transform microwave spectroscopic techniques to identify different types of conformers of BAIBA. These conformers were then isolated in an $\mathrm{N}_{2}$ matrix and characterized vibrationally by IR spectroscopy. In situ narrowband near-IR irradiations of the matrix-isolated BAIBA conformers were used to promote selective conformational conversions, leading both to change the relative populations of the initially present forms and to the production of a new type of conformers of higher energy, which is not initially present in the deposited gas phase sample. The interpretation of the experimental results received support from extensive theoretical calculations performed at different levels of approximation.

\section{EXPERIMENTAL DETAILS}

\section{A. FTMW spectroscopy}

The rotational spectrum of BAIBA was obtained using two different FTMW spectrometers constructed at the University of Valladolid. In both experiments BAIBA samples (R/S- 3-aminoisobutyric acid) were prepared by mixing the powder of the solid (melting point $=179-182{ }^{\circ} \mathrm{C}$ ) with a commercial binder. The mixture was pressed to form cylindrical rods, which were placed in a laser ablation nozzle ${ }^{25}$ to be vaporized using the third $(355 \mathrm{~nm})$ harmonic $(12 \mathrm{~mJ}$ per pulse) of a 20 ps Nd:YAG laser. Then, BAIBA molecules were seeded in the carrier gas, $\mathrm{Ne}$ at backing pressure of 15 bar, to expand adiabatically into the spectrometer cavity.

The first experiments were carried out using a chirped pulse Fourier transform microwave (CP-FTMW) spectrometer with a laser ablation source ${ }^{25-27}$ operating between 6.0 and 18.0 GHz. An arbitrary waveform generator creates a chirped pulse, which is upconverted by a phase-locked dielectric resonator oscillator in a broadband mixer and amplified by a $300 \mathrm{~W}$ traveling wave tube amplifier. The amplified pulse is broadcasted into the vacuum chamber through one microwave horn, interacting with the vaporized molecules in the pulsed jet. Finally, the free induction decay (FID) captured by a second horn is amplified and digitized in a fast oscilloscope. The operation sequence starts with a molecular pulse of $1000 \mu \mathrm{s}$ duration, using the pulsed valve source. After an adequate delay ( 950 $\mu \mathrm{s})$, a laser pulse is used to vaporize the solid. To reduce sample consumption, four separate broadband rotational spectra were acquired in each injection cycle, with a $1400 \mu$ s delay since the origin of the molecular pulse. The individual broadband chirped pulses were separated by $18 \mu \mathrm{s}$. The rotational FID was detected for $10 \mu$ s following each $4 \mu \mathrm{s}$ excitation pulse. To obtain the spectra for BAIBA within the 6-12 GHz range, 120000 averages (30 000 cycles) were acquired. Since the sample injection system has a perpendicular arrangement relative to the microwave field, the transit time of the polarized molecular jet is quite short, and linewidths of the order of $100 \mathrm{kHz}$ full-width-half-maximum (FWHM) are achieved.

The LA-MB-FTMW spectrometer, described in Ref. 44, covering the frequency range of $4-10 \mathrm{GHz}$, was used to record the BAIBA spectra with the resolution necessary to analyze the hyperfine structure due to the presence of a ${ }^{14} \mathrm{~N}$ nucleus in the molecule. The optimal conditions to polarize the molecules in the jet correspond to molecular pulses of about $1.1 \mathrm{~ms}$, followed by MW polarization pulses of $0.3 \mathrm{~ms}$ duration with powers of $1-40 \mathrm{~mW}$. The microwave transient FID was recorded for $100 \mu \mathrm{s}$ in the time domain at 40-100 ns sample intervals and Fourier-transformed to the frequency domain. Due to the collinear disposition between the supersonic jet and the microwave resonator axis, all emission signals appeared to be split into Doppler doublets. The arithmetic mean of the doublets was taken as the rest frequency. The estimated accuracy of the frequency measurements is greater than $3 \mathrm{kHz}$. From 50 to 250 averages were phase-coherently coadded to achieve reasonable signal to noise ratios $(\mathrm{S} / \mathrm{N})$.

\section{B. Matrix isolation FTIR spectroscopy}

For the matrix isolation infrared spectroscopic studies, BAIBA was placed in a specially designed thermoelectrically heatable furnace assembled inside the cryostat. A slow sublimation of the compound $\left(\mathrm{T}=\sim 150{ }^{\circ} \mathrm{C}\right.$ ) allowed for its easy deposition onto the cryostat CsI substrate kept at $13 \mathrm{~K}$, 


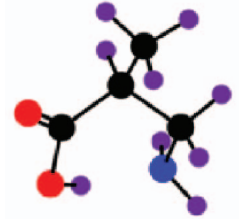

$A_{1}$

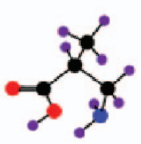

$B_{3}$

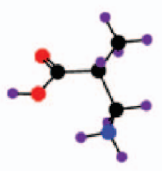

$\mathrm{B}_{9}$

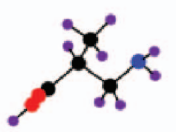

$\mathrm{C}_{4}$

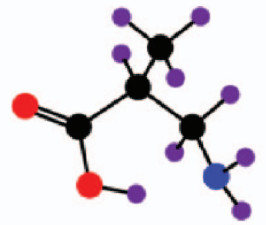

$A_{2}$

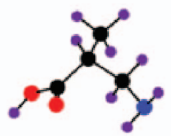

$\mathrm{B}_{4}$
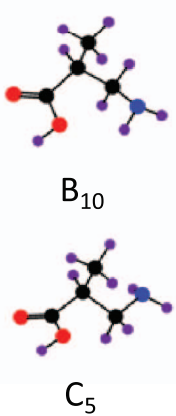

$B_{5}$
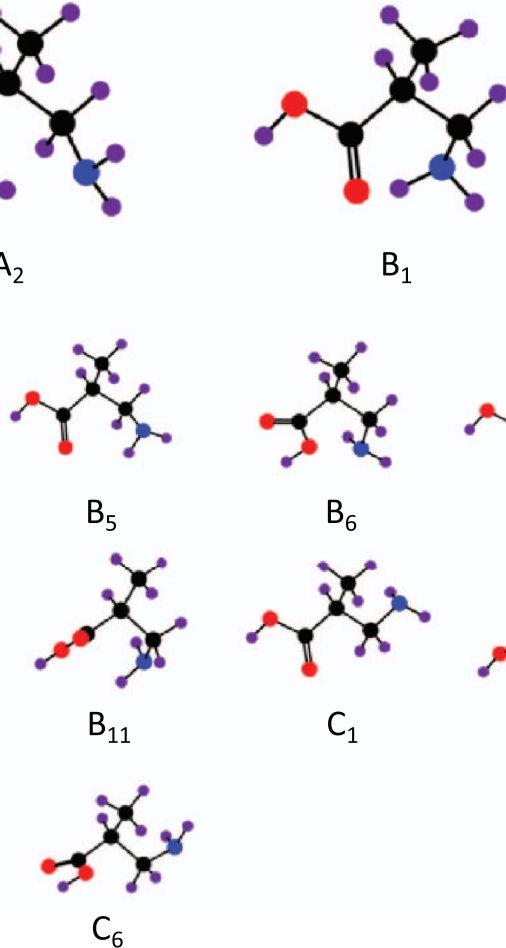

$B_{1}$

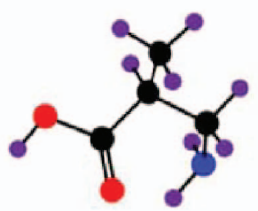

$B_{2}$
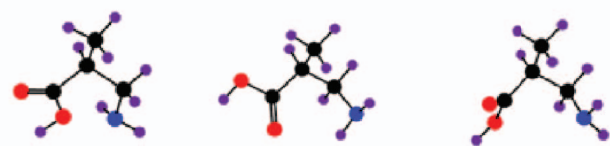

$\mathrm{B}_{7}$

$\mathrm{B}_{8}$
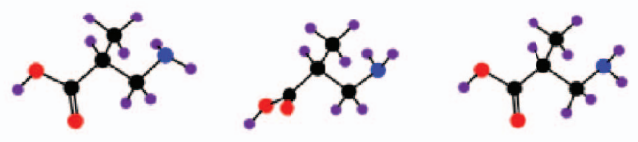

$\mathrm{C}_{1}$

$\mathrm{C}_{2}$

FIG. 1. The 19 lowest energy conformers of BAIBA. Conformers $\mathbf{A}_{\mathbf{1}}, \mathbf{A}_{\mathbf{2}}, \mathbf{B}_{1}$, and $\mathbf{B}_{2}$ were observed experimentally by microwave spectroscopy in this study.

together with a large excess of the $\mathrm{N}_{2}$ host gas $\left(\mathrm{N}_{2}\right.$ :BAIBA molar ratio $>1000$ ) to guarantee good isolation of the compound.

The infrared spectra were registered with $0.5 \mathrm{~cm}^{-1}$ resolution, in the range $4000-400 \mathrm{~cm}^{-1}$, using a Thermo Nicolet Nexus 670 FTIR spectrometer, equipped with a deuterated triglycine sulphate (DTGS) detector and a $\mathrm{KBr}$ beamsplitter. The near-IR spectrum for the studied sample was also recorded in the range $8500-4000 \mathrm{~cm}^{-1}$, to determine the frequency of the $v \mathrm{O}-\mathrm{H}$ overtone vibration of the compound. This was required to tune the laser-MOPO system at the proper frequency during the performed near-IR irradiation experiments.

The narrowband tunable NIR radiation used in the performed irradiation experiments was provided by a Quanta-Ray MOPO-SL optical parametric oscillator (FWHM $\sim 0.2 \mathrm{~cm}^{-1}$, repetition rate $10 \mathrm{~Hz}$, pulse energies between 3 and $10 \mathrm{~mJ}$ ) pumped with a pulsed Nd:YAG laser.

\section{RESULTS AND DISCUSSION}

\section{A. Model calculations: Characterization of the conformational space of BAIBA and of the most relevant intramolecular interactions present in the different conformers of the molecule}

Theory was used to predict the molecular properties relevant to the investigation of the rotational and infrared spectra of BAIBA conformers. The theoretical calculations were first performed at the semiempirical AM1 ${ }^{45}$ level of approximation to find an extended set of low energy conformers of BAIBA. The 40 lowest energy conformers obtained by this procedure were subsequently re-optimized us- ing both the DFT/B3LYP ${ }^{46-48}$ and MP2 ${ }^{49}$ methods and the $6-311++\mathrm{G}(\mathrm{d}, \mathrm{p})$ basis set, ${ }^{50}$ with the GAUSSIAN 03 suite of programs. ${ }^{51}$ In this way, 19 conformers were predicted with relative energies within $1000 \mathrm{~cm}^{-1}\left(\sim 12 \mathrm{~kJ} \mathrm{~mol}^{-1}\right)$. This large number of low energy conformers reflects the richness of the conformational landscape of BAIBA. Each conformer was confirmed to be a local minimum in the potential energy surface by checking that its Hessian matrix did not have any imaginary eigenvalue.

The lowest energy conformers of BAIBA are represented in Figure 1. Their relative energies, Gibbs energies and expected populations in gas phase at room temperature $\left(\sim 25^{\circ} \mathrm{C}\right)$ are provided in Table I. Note that BAIBA has two spectroscopically equivalent (both in the microwave and IR spectra) enantiomeric forms, so that the theoretical calculations considered only one of the enantiomers ( $\mathrm{R}$ form).

In the present work, to name the relevant conformers of BAIBA they have been grouped in 4 different sets, differing in the conformation assumed by the $\mathrm{H}-\mathrm{O}-\mathrm{C}=\mathrm{O}$ and $\mathrm{C}(=\mathrm{O})-\mathrm{C}-\mathrm{C}-\mathrm{N}$ fragments: type $\mathbf{A}$, with the carboxylic group in the trans geometry $\left(\mathrm{H}-\mathrm{O}-\mathrm{C}=\mathrm{O}\right.$ dihedral $\left.\sim 180^{\circ}\right)$ and the $\mathrm{C}(=\mathrm{O})-\mathrm{C}-\mathrm{C}-\mathrm{N}$ moiety in a gauche arrangement, bearing a considerably strong stabilizing $\mathrm{OH} \cdots \mathrm{N}$ intramolecular hydrogen bond; type $\mathbf{B}$, with a cis carboxylic group and a gauche $\mathrm{C}(=\mathrm{O})-\mathrm{C}-\mathrm{C}-\mathrm{N}$ fragment, leading to presence of an intramolecular $\mathrm{H}$-bond of the $\mathrm{NH}$... O type; type $\mathbf{C}$, also with a cis carboxylic group but showing an anti $\mathrm{C}(=\mathrm{O})-\mathrm{C}-\mathrm{C}-\mathrm{N}$ moiety, without any intramolecular H-bond; and type $\mathbf{D}$, with the trans orientation of the carboxylic group and a gauche $\mathrm{C}(=\mathrm{O})-\mathrm{C}-\mathrm{C}-\mathrm{N}$ geometry, and bearing an $\mathrm{NH} \cdots \mathrm{O}=\mathrm{C}$ bond. Within each of the groups, the conformers were numbered according to their relative Gibbs energies (from the lowest to 
TABLE I. Calculated relative energies (zero-point corrected; $\left.\Delta \mathrm{E}^{\mathrm{o}}\right)$ and Gibbs free energies at room temperature $(\mathrm{RT}=298.15 \mathrm{~K})\left(\Delta \mathrm{G}^{\mathrm{o}}\right)$, and predicted populations for the lowest energy conformers of BAIBA. ${ }^{\mathrm{a}}$

\begin{tabular}{|c|c|c|c|c|c|c|c|}
\hline \multirow[b]{2}{*}{ Conformer } & \multicolumn{2}{|c|}{ B3LYP/6-311++G(d,p) } & \multicolumn{2}{|c|}{ MP2/B3LYP/6-311++G(d,p $)^{b}$} & \multicolumn{3}{|c|}{ Mean $^{\mathrm{c}}$} \\
\hline & $\Delta \mathrm{E}^{\mathrm{o}}$ & $\Delta \mathrm{G}^{\mathrm{o}}$ & $\Delta \mathrm{E}^{\mathrm{o}}$ & $\Delta \mathrm{G}^{\mathrm{o}}$ & $\Delta \mathrm{E}^{\mathrm{o}}$ & $\Delta \mathrm{G}^{\mathrm{od}}$ & $\mathrm{p}(\mathrm{RT})^{\mathrm{e}}$ \\
\hline $\mathbf{A}_{1}$ & 0.0 & 0.0 & 0.0 & 1.4 & 0.0 & 0.5 & $15.8(15.8)$ \\
\hline $\mathbf{A}_{2}$ & 4.0 & 4.3 & 2.3 & 4.0 & 3.2 & 4.0 & $3.9(3.9)$ \\
\hline $\mathbf{B}_{1}$ & 2.5 & 0.4 & 0.7 & 0.0 & 1.6 & 0.0 & 19.3 (78.6) \\
\hline $\mathbf{B}_{2}$ & 4.0 & 1.4 & 2.9 & 1.6 & 3.5 & 1.3 & 11.4 \\
\hline $\mathbf{B}_{3}$ & 7.2 & 2.6 & 4.5 & 1.3 & 5.9 & 1.8 & 9.3 \\
\hline $\mathbf{B}_{4}$ & 6.6 & 3.0 & 5.4 & 3.2 & 6.0 & 2.9 & 6.0 \\
\hline $\mathbf{B}_{5}$ & 5.4 & 3.5 & 3.4 & 2.9 & 4.4 & 3.0 & 5.8 \\
\hline $\mathbf{B}_{6}$ & 7.7 & 5.5 & 4.1 & 3.3 & 5.9 & 4.2 & 3.5 \\
\hline $\mathbf{B}_{7}$ & 7.4 & 4.5 & 6.6 & 5.1 & 7.0 & 4.6 & 3.0 \\
\hline $\mathbf{B}_{8}$ & 8.2 & 6.2 & 4.3 & 3.8 & 6.3 & 4.8 & 2.8 \\
\hline $\mathbf{B}_{9}$ & 9.0 & 6.0 & 7.9 & 6.2 & 8.5 & 5.9 & 1.8 \\
\hline $\mathbf{B}_{10}$ & 12.5 & 8.9 & 9.9 & 7.8 & 11.2 & 8.2 & 0.7 \\
\hline $\mathbf{B}_{11}$ & 11.2 & 8.5 & 9.8 & 8.6 & 10.5 & 8.4 & 0.6 \\
\hline $\mathrm{C}_{1}$ & 7.4 & 3.8 & 6.6 & 4.4 & 7.0 & 3.9 & 4.0 \\
\hline $\mathrm{C}_{2}$ & 7.3 & 3.5 & 7.6 & 5.2 & 7.5 & 4.2 & 3.5 \\
\hline $\mathrm{C}_{3}$ & 8.6 & 4.7 & 8.1 & 5.5 & 8.4 & 4.9 & 2.7 \\
\hline $\mathrm{C}_{4}$ & 8.7 & 5.2 & 7.4 & 5.3 & 8.1 & 5.1 & 2.5 \\
\hline $\mathrm{C}_{5}$ & 9.6 & 6.0 & 7.9 & 5.7 & 8.8 & 5.7 & 1.9 \\
\hline $\mathrm{C}_{6}$ & 10.0 & 6.4 & 9.6 & 7.4 & 9.8 & 6.7 & 1.3 \\
\hline
\end{tabular}

${ }^{\mathrm{a}}$ Energies in $\mathrm{kJ} \mathrm{mol}^{-1}$; populations in $\%$. See Figure 1 for pictures of the conformers.

${ }^{\mathrm{b}}$ Zero-point vibrational and thermal corrections extracted from the B3LYP calculations.

${ }^{\mathrm{c}}$ B3LYP-MP2 average values.

${ }^{\mathrm{d}}$ Since the directly calculated $\Delta \mathrm{G}^{\mathrm{o}}$ mean B3LYP-MP2 values yield the minimum value (for $\mathbf{B}_{1}$ ) equal to $0.2 \mathrm{~kJ}^{-1}$, all values were recalculated in relation to this value.

${ }^{\mathrm{e}}$ Populations for all conformers in gas phase at room temperature $(298.15 \mathrm{~K})$ calculated using the average $\Delta \mathrm{G}^{\mathrm{o}}$ values and obtained assuming the Boltzmann equilibrium; values in parentheses correspond to the approximate populations in the as-deposited cryogenic matrices assuming conformational relaxation of all $\mathbf{C}$-type conformers and $\mathbf{B}$-type conformers to the most stable cis $\mathrm{COOH}$ conformer, $\mathbf{B}_{\mathbf{1}}$ (see text for discussion).

the highest energy, according to the average values obtained by the two methods of calculation used; see Table I).

According to both B3LYP and MP2 calculations, the two conformers possessing the strong stabilizing $\mathrm{OH} \cdots \mathrm{N}$ intramolecular hydrogen bond (type $\mathbf{A}$ ) correspond to the first $\left(\mathbf{A}_{1}\right)$ and third $\left(\mathbf{A}_{2}\right)$ lowest energy $\left(\Delta \mathrm{E}^{\mathrm{O}}\right)$ forms. Note that in these conformers the arrangement of the carboxylic group is trans $\left(\mathrm{H}-\mathrm{O}-\mathrm{C}=\mathrm{O}\right.$ dihedral $\sim 180^{\circ}$ ), which is well-known to be intrinsically unfavored regarding the cis one $(\mathrm{H}-\mathrm{O}-$ $\mathrm{C}=\mathrm{O}$ dihedral $\sim 0^{\circ}$; observed in both type $\mathbf{B}$ and type $\mathbf{C}$ conformers of BAIBA) by ca. $10-20 \mathrm{~kJ} \mathrm{~mol}^{-1} \cdot{ }^{43,52-54}$ This fact then stresses the structural relevance of the $\mathrm{OH} \cdots \mathrm{N}$ hydrogen bond in these two conformers. Moreover, it can also be noticed in Table I that, when entropy effect is taken into account (compare the relative Gibbs energies values with the $\Delta \mathrm{E}^{\mathrm{o}}$ data), the two $\mathbf{A}$ type conformers become destabilized compared to both B and C type conformers. Such entropyconnected relative destabilization is also a direct consequence of the presence of the strong $\mathrm{OH} \cdots \mathrm{N}$ intramolecular hydrogen bond in type $\mathbf{A}$ conformers, which reduce the structural mobility in these forms. In consequence of this effect, in the gas phase equilibrium at room temperature $\left(\sim 25^{\circ} \mathrm{C}\right)$, conformer $\mathbf{B}_{1}$ is predicted to be the most populated (lowest $\Delta G^{\circ}$ ) BAIBA conformer. The importance of entropy in determining the relative gas phase abundances of conformers of other similar molecular systems has already been pointed out before, e.g., for GABA, phenylalanine, tryptophane, and serine. ${ }^{17,55-57}$
The strong $\mathrm{OH} \cdots \mathrm{N}$ intramolecular hydrogen bond in type A conformers leads also to other relevant unique characteristics of these two forms. First, it makes the energy barriers separating these forms from other conformers considerably larger than for conformers of types $\mathbf{B}$ and $\mathbf{C}$, since a substantial amount of energy is required to break this hydrogen bond [the energy of the intramolecular $\mathrm{OH} \cdots \mathrm{N}$ bond in BAIBA can be expected to be similar to that in $\beta$-alanine, where the barrier for internal rotation around the $\mathrm{C}-\mathrm{O}$ bond counted from the most stable conformer bearing the $\mathrm{OH} \cdots \mathrm{N}$ interaction was found to be of $\sim 50 \mathrm{~kJ} \mathrm{~mol}^{-1.58}$ similar values for this barrier were also predicted for phenylalanine $(\sim 50 \mathrm{~kJ}$ $\left.\mathrm{mol}^{-1}\right)^{56}$ and glycine $\left.\left(\sim 65 \mathrm{~kJ} \mathrm{~mol}^{-1}\right)^{59}\right]$. Secondly, the $v \mathrm{O}_{-}$ $\mathrm{H}$ stretching frequency in type $\mathbf{A}$ conformers must be noticeably lower than in all the other conformers, where the $\mathrm{O}-\mathrm{H}$ group is not involved as a donor in any intramolecular $\mathrm{H}$ bond. In third place, the trans arrangement of the carboxylic group required for the establishment of the hydrogen bond implies that the carbonyl bond has a larger double bond character than for the $\mathbf{B}$ and $\mathbf{C}$ type conformers (with a cis carboxylic group) ${ }^{60}$ and, consequently, a higher $\nu \mathrm{C}=\mathrm{O}$ stretching frequency (compared to some of the $\mathbf{B}$ type forms, this trend shall also be reinforced due to the involvement of the carbonyl oxygen atom as acceptor in the NH...O intramolecular hydrogen bond in these latter forms). The trans carboxylic acid arrangement leads also to substantially larger dipole moments for $\mathbf{A}_{1}$ and $\mathbf{A}_{2}$ compared with those of type $\mathbf{B}$ and $\mathbf{C}$ forms. The dipole moment components of the different BAIBA con- 
TABLE II. Experimental spectroscopic parameters for the four observed conformers of BAIBA compared with those predicted at the MP2/6-311++G(d,p) level of theory. ${ }^{\mathrm{a}}$

\begin{tabular}{|c|c|c|c|c|c|c|c|c|}
\hline & \multicolumn{2}{|c|}{$\mathbf{A}_{1}$} & \multicolumn{2}{|c|}{$\mathbf{A}_{2}$} & \multicolumn{2}{|r|}{$\mathbf{B}_{1}$} & \multicolumn{2}{|r|}{$\mathbf{B}_{2}$} \\
\hline & Theor. & Expt. & Theor. & Expt. & Theor. & Expt. & Theor. & Expt. \\
\hline$A(\mathrm{MHz})$ & 3400.29 & $3393.48469(54)$ & 3732.17 & $3718.866(11)$ & 3334.24 & $3366.13261(45)$ & 3266.96 & $3331.28250(64)$ \\
\hline$B(\mathrm{MHz})$ & 2436.57 & $2427.93020(60)$ & 2165.26 & $2167.59856(42)$ & 2272.24 & $2255.12717(68)$ & 2208.64 & $2206.86411(52)$ \\
\hline$C(\mathrm{MHz})$ & 1513.40 & $1507.12258(55)$ & 1730.69 & $1716.81063(55)$ & 1622.12 & $1597.28176(51)$ & 1636.26 & $1599.97757(67)$ \\
\hline$\Delta_{\mathrm{J}}(\mathrm{kHz})$ & & $0.201(31)$ & & $0.297(16)$ & & $0.547(17)$ & & $0.0668(67)$ \\
\hline$\mu_{\mathrm{a}}(\mathrm{D})$ & 5.7 & $\ldots$ & 6.4 & $\ldots$ & 0.1 & $\ldots$ & -1.6 & $\ldots$ \\
\hline$\mu_{\mathrm{b}}(\mathrm{D})$ & -2.9 & $\ldots$ & -1.2 & $\ldots$ & -1.1 & $\ldots$ & -1.2 & $\ldots$ \\
\hline$\mu_{\mathrm{c}}(\mathrm{D})$ & 0.6 & $\ldots$ & -0.4 & $\ldots$ & -0.4 & $\ldots$ & 1.4 & $\ldots$ \\
\hline$\chi_{\text {aа }}(\mathrm{MHz})$ & 0.2041 & $0.1549(41)$ & -1.5444 & $-1.4760(40)$ & 1.6414 & $1.5911(63)$ & -4.1692 & $-3.7700(17)$ \\
\hline$\chi_{\mathrm{bb}}(\mathrm{MHz})$ & -2.0780 & $-1.8931(49)$ & 0.5786 & $0.387(10)$ & 2.5752 & $2.3937(71)$ & 2.5814 & $2.41076(71)$ \\
\hline$\chi_{\mathrm{cc}}(\mathrm{MHz})$ & 1.8739 & $1.7383(49)$ & 0.9659 & $1.089(10)$ & -4.2166 & $-3.9847(71)$ & 1.5878 & $1.35924(71)$ \\
\hline$\sigma^{\mathrm{b}}(\mathrm{kHz})$ & & 3.7 & & 3.0 & & 3.0 & & 1.5 \\
\hline $\mathrm{N}^{\mathrm{c}}$ & & 34 & & 22 & & 21 & & 20 \\
\hline
\end{tabular}

${ }^{\mathrm{a}} A, B$, and $C$ are the rotational constants; $\mu_{\mathrm{a}}, \mu_{\mathrm{b}}$, and $\mu_{\mathrm{c}}$ are the electric dipole moment components; and $\chi_{\mathrm{aa}}, \chi_{\mathrm{bb}}$, and $\chi_{\mathrm{cc}}$ are elements of the ${ }^{14} \mathrm{~N}$ nuclear quadrupole coupling tensor. ${ }^{\mathrm{b}} \mathrm{rms}$ deviation of the fit.

${ }^{\mathrm{c}}$ Number of quadrupole hyperfine components.

formers are relevant properties in determining their rotational signature and can be found in Table II (only for the conformers observed in this study by microwave spectroscopy; see Sec. III B) or Table S-I ${ }^{61}$ (for all the 19 low energy conformers shown in Figure 1).

Contrarily to the $\mathrm{OH} \cdots \mathrm{N}$ bond present in $\mathbf{A}_{1}$ and $\mathbf{A}_{2}$ forms, the intramolecular $\mathrm{NH}$... O hydrogen bond existing in type $\mathbf{B}$ conformers is weak and its structural implications as well as its effects on the conformational dynamics can be expected to be of low importance. In consonance with this, only 3 conformers of $\mathbf{B}$ type $\left(\mathbf{B}_{\mathbf{1}}, \mathbf{B}_{\mathbf{2}}\right.$ and $\left.\mathbf{B}_{\mathbf{3}}\right)$ have a lower energy than the most stable $\mathbf{C}$ type conformer, which does not possess any intramolecular hydrogen bond. In addition, the entropy

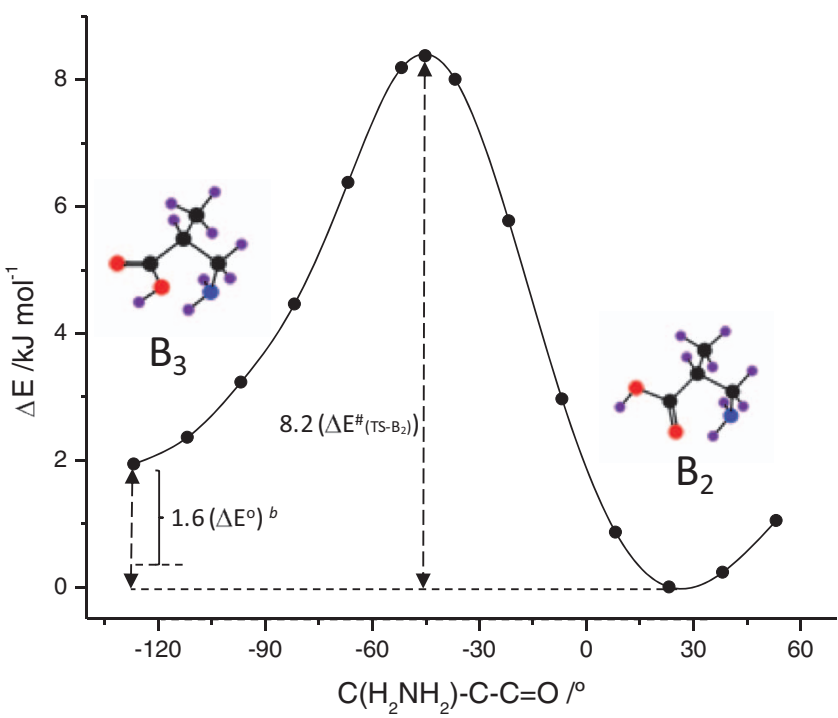

FIG. 2. MP2/6-311++G(d,p) calculated potential energy profile for interconversion between conformers $\mathbf{B}_{2}$ and $\mathbf{B}_{3}$. The calculated $\mathbf{B}_{3}-\mathbf{B}_{2}$ energy difference $\left(\Delta \mathrm{E}_{\left(\mathrm{B}_{3}-\mathrm{B}_{2}\right)}\right)$ is $1.9 \mathrm{~kJ} \mathrm{~mol}^{-1}$, while the zero-point corrected MP2/B3LYP/6-311++G $(\mathrm{d}, \mathrm{p})$ energy difference $\left(\Delta \mathrm{E}_{\left(\mathrm{B}_{3}-\mathrm{B}_{2}\right)}^{\mathrm{O}}\right)$ is $1.6 \mathrm{~kJ} \mathrm{~mol}^{-1}$ (see also Table I). The barrier to conformational isomerization presented in the figure does not take into account the zero-point corrections. contributions to the Gibbs energies of both $\mathbf{B}$ and $\mathbf{C}$ type conformers are approximately equal (see Table I), and the energy barriers interconverting $\mathbf{B}$ type conformers are small [as an example, Figure 2, presenting the potential energy profile for interconversion between forms $\mathbf{B}_{\mathbf{2}}$ and $\mathbf{B}_{\mathbf{3}}$ by internal rotation around the $\mathrm{C}-\mathrm{C}_{\alpha}$ bond is provided, showing a $\mathbf{B}_{\mathbf{2}} \rightarrow \mathbf{B}_{\mathbf{3}}$ barrier of $8.2 \mathrm{~kJ} \mathrm{~mol}^{-1}\left(6.3 \mathrm{~kJ} \mathrm{~mol}^{-1}\right.$ in the reverse direction)].

Low internal rotation barriers around $\mathrm{C}-\mathrm{N}, \mathrm{C}-\mathrm{C}_{\alpha}$ and $\mathrm{C}_{\beta}-\mathrm{C}_{\alpha}$ bonds have been reported for other amino acids. For example, barriers as low as 1.5 and $0.4 \mathrm{~kJ} \mathrm{~mol}^{-1}$ were found for internal rotations around the $\mathrm{C}-\mathrm{N}$ and $\mathrm{C}-\mathrm{C}_{\alpha}$ bonds in alanine, ${ }^{59}$ while for phenylalanine these barriers were found to be in the ranges 5-12 $\mathrm{kJ} \mathrm{mol}^{-1}$ and 7-13 $\mathrm{kJ} \mathrm{mol}^{-1}$, respectively. ${ }^{56}$ For $\beta$-alanine, which is structurally closer to BAIBA, extensive calculations of the conformational isomerization barriers yielded upper limits for barriers around the $\mathrm{C}-\mathrm{N}, \mathrm{C}-\mathrm{C}_{\alpha}$, and $\mathrm{C}_{\beta}-\mathrm{C}_{\alpha}$ bonds of ca. 13,8 , and $13 \mathrm{~kJ} \mathrm{~mol}^{-1}$, respectively. ${ }^{56}$

As shown in detail below, both the relative structural rigidity of conformers of type $\mathbf{A}$, ensured by their strong intramolecular $\mathrm{OH} \cdots \mathrm{N}$ bond, and the conformational flexibility of type $\mathbf{B}$ and $\mathbf{C}$ conformers were found to be of fundamental importance in determining the spectroscopic properties exhibited by BAIBA in the microwave as well as in the matrix isolation infrared studies described in Secs. III B and III C.

\section{B. Rotational spectra: Experimental identification and characterization of the 4 lowest energy conformers of BAIBA}

Experiments with the CP-FTMW spectrometer were used to record the $12 \mathrm{GHz}$ broadband rotational spectrum of BAIBA from 6 to $18 \mathrm{GHz}$ (Figure 3). The analysis of this spectrum has been carried out using the jb95 program package. ${ }^{62}$ It was easy to distinguish two sets of progressions composed for three intense $\mu_{\mathrm{a}}-\mathrm{R}$-branch transitions with $J$ 


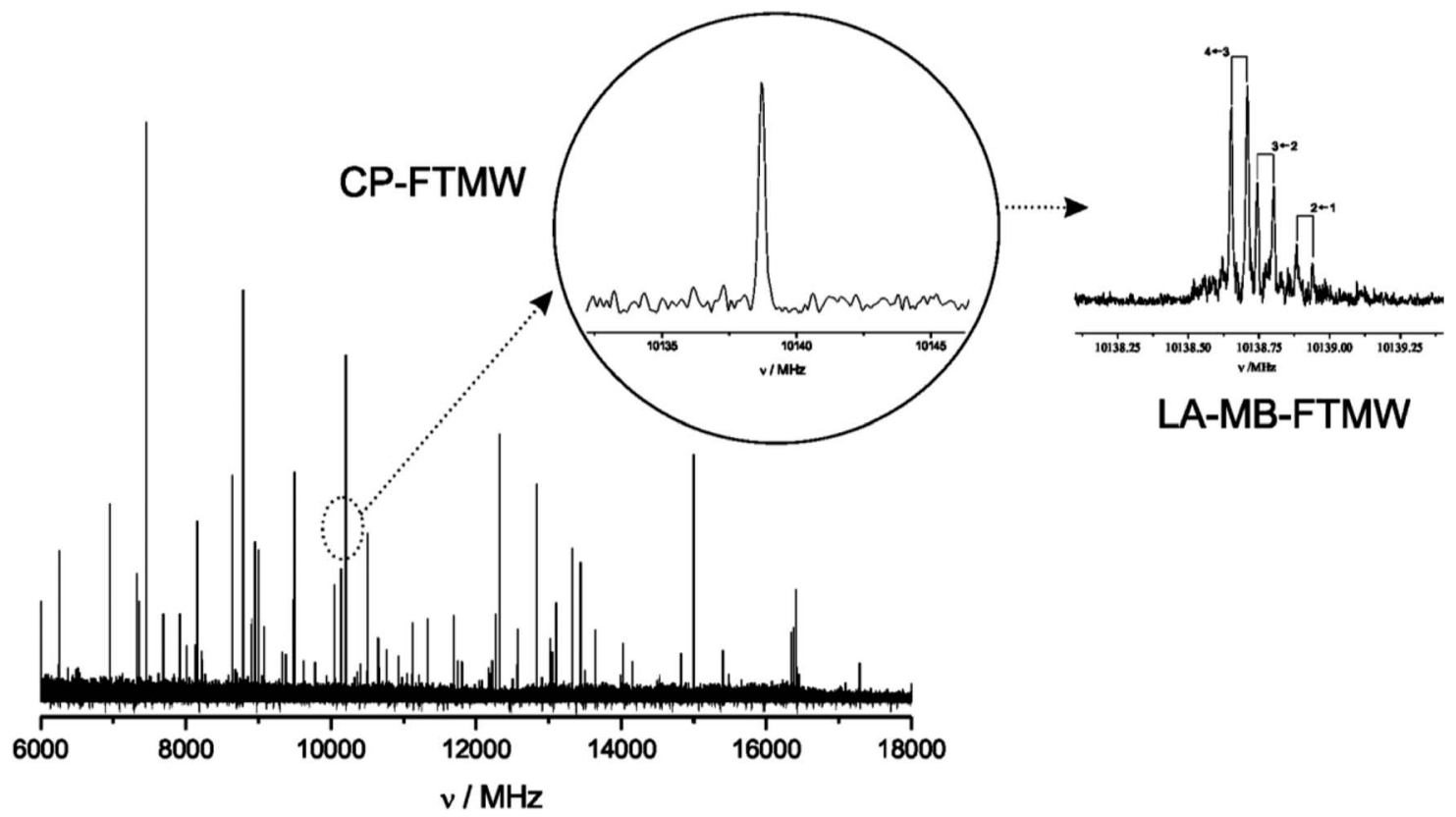

FIG. 3. Broadband CP-FTMW rotational spectrum of BAIBA in the 6-18 GHz region. Top insets: (left) detail of the CP-FTMW spectrum showing the feature ascribed to the $3_{03}-2_{12}$ transition for conformer $\mathbf{B}_{1}$; (right) high-resolution LA-MB-FTMW spectrum of the same transition, showing the quadrupole components labeled for conformer $\mathbf{B}_{1}$.

angular momentum quantum number ranging from 2 to 4 , revealing the presence of two conformers, designated here as $\mathbf{1}$ and 2. The rotational signature of a third conformer, labeled as $\mathbf{3}$, was identified in the spectrum from the measurements of very intense $\mu_{\mathrm{b}}-\mathrm{R}$-branch transitions. Some additional small $\mu_{\mathrm{a}}-\mathrm{R}$-branch lines could be assignable to a fourth conformer (4).

BAIBA possesses one ${ }^{14} \mathrm{~N}$ nucleus $(I=1)$ with a nonzero quadrupole moment, which interacts with the electric field gradient created at the site of the $\mathrm{N}$ nucleus by the rest of molecular charges. This interaction leads to the coupling between the ${ }^{14} \mathrm{~N}$ nuclear spin $(I=1)$ and the overall angular momentum, giving rise to a hyperfine structure in the rotational spectrum. As shown in Figure 3, the resolution attained with the CP-FTMW technique is not sufficient to analyze this hyperfine structure, due to the perpendicular arrangement between the supersonic jet and the microwave beam. For this reason, BAIBA rotational spectrum was also probed by using the subdoppler resolution of our LA-MB-FTMW spectrometer. This made possible to resolve the hyperfine structure for all observed conformers. Figure 3 (top right inset) shows, as an example, the hyperfine structure of the $3_{03}-2_{12}$ transition with the quadrupole components labeled for the most abundant form.

All the measured quadrupole coupling hyperfine components for the different rotamers (collected in Tables S-II to S$\mathrm{V}$ of the supplementary material $)^{61}$ were fitted using a semirigid rotor Hamiltonian $H_{R}{ }^{(A)},{ }^{63}$ supplemented with a $H_{Q}$ term to account for the nuclear quadrupole coupling contribution. ${ }^{64}$ The Hamiltonian was set up in the coupled basis set $I+J$ $=F$ and diagonalized in blocks of $F$. The energy levels involved in each transition are thus labeled with the quantum numbers $J, K_{-1}, K_{+1}, F$. The experimentally determined parameters are: the rotational constants $(A, B$, and $C)$, which provide information on the mass distribution of each conformer, and the quadrupole coupling constants $\left(\chi_{\mathrm{aa}}, \chi_{\mathrm{bb}}\right.$, and $\left.\chi_{\mathrm{cc}}\right)$, which yield information about the electronic environment of the ${ }^{14} \mathrm{~N}$ nucleus. All those constants for the observed conformers are given in Table II.

Conformational identification of the observed rotamers has been achieved by comparing the experimentally determined molecular properties of Table II with those predicted $a b$ initio of Table S-I. ${ }^{61}$ The rotational constants provide information on the mass distribution of each rotamer and are normally conclusive in the conformational assignments. However, as can be seen in Tables S-I ${ }^{61}$ and II these experimental parameters of each rotamer are compatible with those predicted for more than one conformer of BAIBA, and the identification of each rotamer as a particular conformer cannot rest only on the rotational constants. Otherwise, the quadrupole coupling constants are very sensitive to the chemical environment around the ${ }^{14} \mathrm{~N}$ nucleus and to the $\mathrm{NH}_{2}$ group orientation with respect to the principal axis system. In $\mathrm{N}$-containing compounds, they have proven to be of extraordinary value for conformer/tautomer identification, allowing the discrimination between species with very similar molecular shapes, and therefore very similar rotational constants. ${ }^{6-20}$ Comparison of the quadrupole coupling constants of Tables $\mathrm{S}-\mathrm{I}^{61}$ and II leads to the definitive identification of the observed rotamers $\mathbf{1}, \mathbf{2}$, $\mathbf{3}$, and $\mathbf{4}$ to the low energy conformers $\mathbf{A}_{1}, \mathbf{A}_{\mathbf{2}}, \mathbf{B}_{\mathbf{1}}$, and $\mathbf{B}_{2}$, respectively.

Relative intensity measurements were done on different transitions of the three assigned conformers in order to roughly estimate their relative abundances in the supersonic jet. $^{5,65}$ The relative abundances of the conformers in the supersonic expansion are the result of a series of processes that include the laser-vaporization of solid BAIBA, the seeding of BAIBA molecules in the region where the laser ablation plume and the carrier gas stream cross each other, and the collisional cooling occurring in the subsequent supersonic 
expansion. Laser ablation is a complex process that may result in high translational temperatures and collisionally induced vibration and rotational cooling. The relative population of the different conformers would be brought close to that of thermodynamic equilibrium at the temperature of the carrier gas only if a high collision rate exists in the seeding region. During the expansion, collisional relaxation of higher energy conformers to lower energy conformers may occur.

The population ratios estimated for the observed BAIBA conformers follow the order $\mathbf{B}_{1} \gg \mathbf{A}_{1}>\mathbf{A}_{2}$, with the population of $\mathbf{B}_{2}$ being also very small compared to $\mathbf{B}_{1}$ and $\mathbf{A}_{1}$, but difficult to quantify relatively to $\mathbf{A}_{2}$, due to the large differences between the dipole moment components of these two less abundant forms (see Table II). The experimental observation of only conformers $\mathbf{A}_{1}, \mathbf{A}_{2}, \mathbf{B}_{1}$, and $\mathbf{B}_{2}$ in the rotational spectra of BAIBA contrasts with the predicted equilibrium populations for the gas phase (see Table I), which indicated that the populations of $\mathbf{A}_{\mathbf{1}}$ and $\mathbf{B}_{\mathbf{1}}$ should be nearly the same under equilibrium conditions and that other conformers (in particular, conformer $\mathbf{B}_{\mathbf{3}}$ ) might also had enough population to allow for their experimental observation.

The experimental results can, however, be explained assuming a high collision rate in the seeding region leading to near equilibrium, followed by selective collisional relaxation, in the supersonic expansion, of conformers of types $\mathbf{B}$ and $\mathbf{C}$. As discussed before, these conformers show a high conformational flexibility due to their low energy barriers for conformational isomerization. Conformational relaxation through specific low-barrier interconversion pathways in the potential energy surface may then occur by collisions with the inert carrier gas in the early stages of the expansion. Investigations carried out in systems with a single torsional degree of freedom estimate barrier thresholds about $5 \mathrm{~kJ} \mathrm{~mol}^{-1}$, 66 though larger barriers $\left(\sim 12 \mathrm{~kJ} \mathrm{~mol}^{-1}\right)$ have been proposed in systems with several degrees of freedom. ${ }^{67,68}$ Conformational relaxation was previously proposed in jet-cooled rotational studies of glycine, ${ }^{59}$ alanine ${ }^{5,59}$ and other amino acids $^{6,7,9-12}$ to rationalize the non-observation of conformers bearing weak intramolecular hydrogen bonds of $\mathrm{N}-\mathrm{H} \cdots \mathrm{O}$ type. In the case of BAIBA, since conformer $\mathbf{B}_{\mathbf{1}}$ is the most stable among all $\mathbf{B}$ and $\mathbf{C}$ conformers, its population increased very much due to the conformational relaxation, while conformer $\mathbf{B}_{\mathbf{2}}$ (the second most stable among $\mathbf{B}$ and $\mathbf{C}$ forms) could still survive in the jet with a minor population.

On the other hand, the high energy barriers separating the two A type conformers from the other conformers make the conformational relaxation inefficient in these cases, so that the populations of forms $\mathbf{A}_{\mathbf{1}}$ and $\mathbf{A}_{\mathbf{2}}$ detected in the microwave spectra shall correspond to those present in the quasiequilibrium seeding region.

It shall be also noticed that all $\mathbf{B}$ and $\mathbf{C}$ type conformers of BAIBA have predicted values of the dipole moment components quite low, making difficult their experimental observation. This factor, in combination with conformational relaxation, may result in intensities of rotational transitions for the eventually surviving residual population of these conformers to be below the sensitivity limit of the used instrumentation. On the other hand, conformer $\mathbf{A}_{2}$ could be easily detected in the supersonic expansion despite its expected lower population, in consequence of the high value of its $\mu_{\mathrm{a}}$ dipole moment component (predicted value: 6.4 D).

\section{Matrix isolation infrared spectra: The vibrational signature of $A$ and $B$ type conformers of BAIBA and the near-IR induced $B_{1} \rightarrow A_{1}$ and $B_{1} \rightarrow D_{1}$ conversions}

In the matrix isolation infrared studies, a solid sample of BAIBA was sublimated $\left(\mathrm{T}=\sim 150{ }^{\circ} \mathrm{C}\right)$ in a mini-oven assembled inside the cryostat. Vapors of the compound were co-deposited with a large excess of $\mathrm{N}_{2}$ onto a CsI cooled down to $13 \mathrm{~K}$. The obtained spectrum of the as-deposited matrix is shown in Figure 4.

As it can be noticed in Figure 4, most of the bands observed in the spectrum exhibit multiplet structure. These multiplets can result from contributions of several conformers or be a consequence of trapping of the same species in different matrix sites (site splitting). ${ }^{34}$ To differentiate between the two possibilities is not easy in the present case, because of the extensive structural similarity of the conformers belonging to a given group $(\mathbf{A}, \mathbf{B}, \mathbf{C})$, which can be expected to lead to small frequency shifts of the order of magnitude of those resulting from site splitting, and also because in both cases temperature variation may lead to intensity redistribution of the different band components. Hence, the presence in the matrix of various conformers within each group cannot be excluded.

However, the results discussed in Secs. III A and III B indicated that in BAIBA conformational cooling is an easy process, in particular in case of the conformers of types $\mathbf{B}$ and C. In a matrix isolation effusive experiment, the vapor being deposited is at equilibrium at the temperature used to sublimate the compound (in the present case of $\sim 150{ }^{\circ} \mathrm{C}$ ), and conformational cooling occurs during the landing of the hot gaseous beam onto the cooled $(13 \mathrm{~K})$ optical substrate of the cryostat. Energy dissipation is assisted by the lattice phonons. Extensive conformational cooling can then take place during deposition of the matrix in case of BAIBA conformers separated by small energy barriers, like those belonging to groups $\mathbf{B}$ and $\mathbf{C}$. Accordingly, it seems most probable that BAIBA

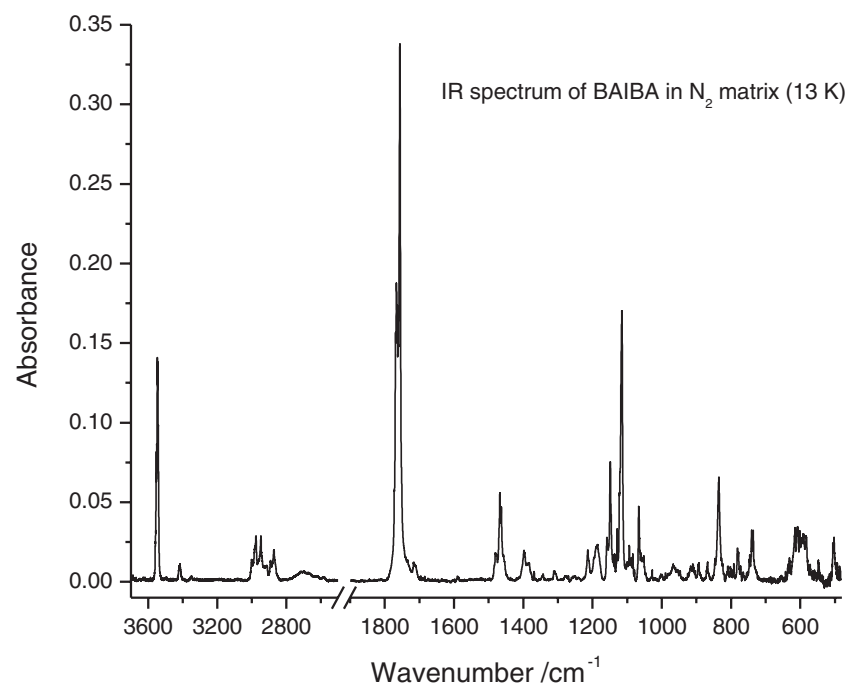

FIG. 4. Infrared spectrum of BAIBA in a $\mathrm{N}_{2}$ matrix at $13 \mathrm{~K}$. 
exist in the as-deposited matrix mainly as the $\mathbf{A}_{\mathbf{1}}$ and $\mathbf{B}_{\mathbf{1}}$ conformers, the latter resulting from extensive conformational cooling during deposition of conformers of $\mathbf{B}$ and $\mathbf{C}$ types. Conformer $\mathbf{A}_{\mathbf{2}}$ shall also be present in the matrix, but its expected low population (see Table I) and the close similarity of its infrared spectra with that of the major $\mathbf{A}_{\mathbf{1}}$ conformer precludes its experimental identification. The same may also be stated in relation with conformer $\mathbf{B}_{2}$, though this conformer most probably also converts to $\mathbf{B}_{\mathbf{1}}$ during deposition of the matrix.

The discrimination between the bands originated in $\mathbf{A}_{\mathbf{1}}$ and $\mathbf{B}_{1}$ conformers could not be done by annealing of the matrices within the accessible temperature range (above ca. $30 \mathrm{~K}$ the matrix started to deteriorate and molecular diffusion initiated, so that BAIBA aggregates started to contribute to the spectrum significantly). However, analysis of the $v \mathrm{O}-\mathrm{H}$ stretching region of the spectrum of the as-deposited matrix allowed for a clear identification of the bands due to this vibration in the two conformers. The band due to $\mathbf{B}_{1}$, where the $\mathrm{OH}$ group is not participating in any hydrogen bond as donor, is observed at the typical frequency of a "free" $\nu \mathrm{O}-$ $\mathrm{H}$ stretching mode of a monomeric carboxylic group, i.e., at ca. $3550 \mathrm{~cm}^{-1}$. On the other hand, the $\nu \mathrm{O}-\mathrm{H}$ vibration of the $\mathrm{O}-\mathrm{H} \cdots \mathrm{N}$ hydrogen bonded conformer $\mathbf{A}_{\mathbf{1}}$ gives rise to the very broad band with maximum absorbance at ca. 2700 $\mathrm{cm}^{-1}$ (which shall also contain a minor contribution from $\mathbf{A}_{2}$ ). Other modes mainly localized in the carboxylic moiety were predicted by the calculations to give rise to intense infrared bands appearing at quite different frequencies in $\mathbf{A}_{\mathbf{1}}$ and $\mathbf{B}_{\mathbf{1}}$. For example, in $\mathbf{A}_{\mathbf{1}}$ the $\nu \mathrm{C}-\mathrm{O} / \delta \mathrm{COH}$ mixed modes are predicted to occur at 1466 and $1211 \mathrm{~cm}^{-1}$, with intensities of 248.9 and $97.4 \mathrm{~km} \mathrm{~mol}^{-1}$, respectively, while the same vibrations in $\mathbf{B}_{\mathbf{1}}$ are predicted at much lower frequencies, 1293.3 and $1115.1 \mathrm{~cm}^{-1}$, with intensities of 3.9 and $189.8 \mathrm{~km} \mathrm{~mol}^{-1}$. The two bands of the $\mathbf{A}_{\mathbf{1}}$ form and the intense one of the $\mathbf{B}_{\mathbf{1}}$ form appear in spectral regions where no other intense bands are predicted by the calculations, and could be easily ascribed to the features observed in the $1470-1460 \mathrm{~cm}^{-1}$ range, 1213 and $1115 \mathrm{~cm}^{-1}$, respectively. Nevertheless, the full assignment of the spectrum to the two major conformers $\mathbf{A}_{1}$ and $\mathbf{B}_{1}$ was made possible by means of the performed near-IR irradiation experiments, as described below. The assignments are provided in Table S-VI, ${ }^{61}$ where the observed frequencies are correlated with the corresponding calculated ones for the two conformers.

In the near-IR spectra of BAIBA, the first overtone of the $v \mathrm{O}-\mathrm{H}$ vibration of the $\mathbf{B}_{\mathbf{1}}$ conformer was observed in the $3930-3940 \mathrm{~cm}^{-1}$ range as a site-splitted multicomponent band. On the other hand, as for the fundamental vibration, the vO-H overtone of the $\mathbf{A}_{\mathbf{1}}$ conformer shall give rise to a very broad band at much lower frequency. Together with the low intensity expected for the overtone, the broadness of the band precludes its experimental observation (it appears "diluted" in the baseline). Once the position of the $\nu \mathrm{O}-\mathrm{H}$ overtone of $\mathbf{B}_{1}$ was experimentally determined, irradiations of the matrixisolated BAIBA at selected frequencies within the envelope of the band were performed.

As previously observed for other molecules containing the $\mathrm{O}-\mathrm{H}$ moiety, ${ }^{41-43}$ selective vibrational excitation of the
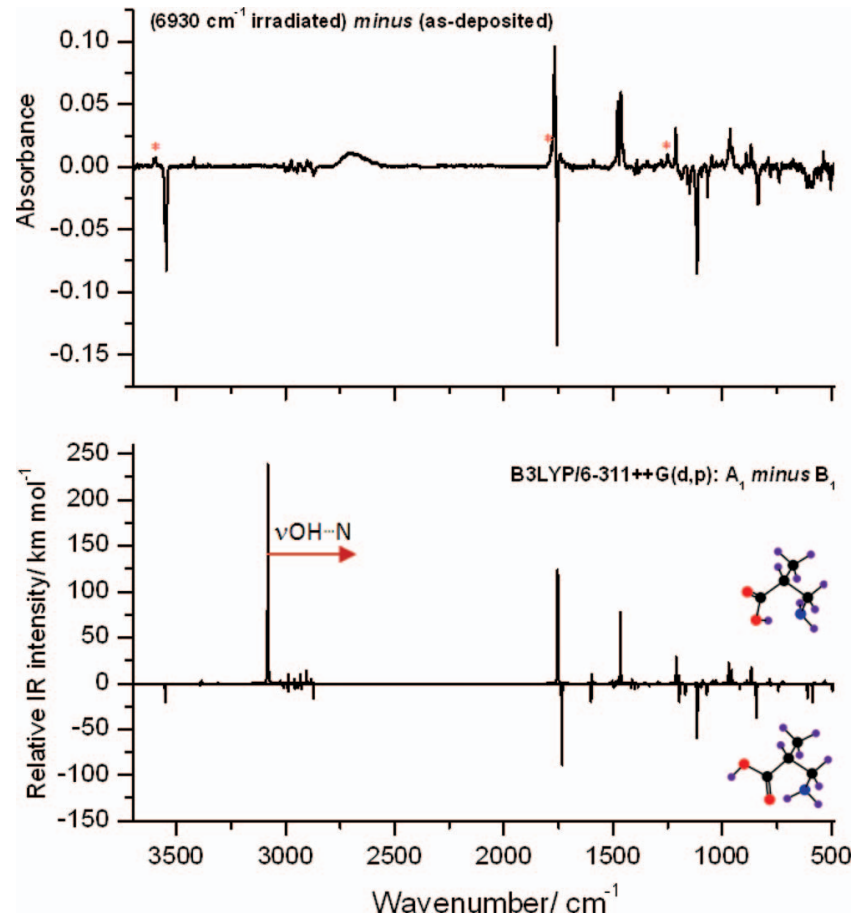

FIG. 5. Difference IR spectrum (near-IR irradiated BAIBA: $\mathrm{N}_{2}$ matrix at $6930 \mathrm{~cm}^{-1}$ minus as-deposited matrix) (top), compared with the difference simulated spectrum for conformers $\mathbf{A}_{1}$ (bands pointing up) and $\mathbf{B}_{1}$ (down) (bottom). In the simulated spectrum, bands were represented by Lorentzian profiles having a full-width at half maximum (FWHM) of $2 \mathrm{~cm}^{-1}$ centered at the calculated frequencies scaled by 0.993 (below $1650 \mathrm{~cm}^{-1}$ ), 0.965 (above $1650 \mathrm{~cm}^{-1}$ ) and $0.945\left(\nu \mathrm{O}-\mathrm{H}\right.$ and $\nu \mathrm{NH}_{2}$ stretching modes). Note that even after the applied scaling the calculated $\nu \mathrm{O}-\mathrm{H}$ frequency in the $\mathrm{O}-\mathrm{H} \cdots \mathrm{N}$ hydrogen bonded conformer $\mathbf{A}_{1}$ is considerably overestimated (as evidenced by the arrow). The most characteristic new bands emerging upon irradiation are marked with a red asterisk, and are ascribed to conformer $\mathbf{D}_{1}$ (see text and Figure 6).

first $\nu \mathrm{O}-\mathrm{H}$ overtone of the $\mathbf{B}_{\mathbf{1}}$ conformer of BAIBA allowed to promote the internal rotation of the $\mathrm{O}-\mathrm{H}$ group and convert this conformer into other conformers. Note that the energy of the exciting photons is of ca. $50 \mathrm{~kJ} \mathrm{~mol}^{-1}$, i.e., above to the height of the barrier of internal rotation which converts the cis carboxylic group existing in conformer $\mathbf{B}_{1}$, into a trans carboxylic group. As shown in Figure 5, the performed irradiations led to major conversion of conformer $\mathbf{B}_{1}$ into conformer $\mathbf{A}_{\mathbf{1}}$, which implies also that a simultaneous internal rotation around the $\mathrm{C}-\mathrm{C}_{\alpha}$ bond takes place (see Figure 1). Indeed, the spectra of the reactant and product conformers fit very well those predicted for $\mathbf{B}_{\mathbf{1}}$ and $\mathbf{A}_{\mathbf{1}}$.

Very interestingly, in the spectrum of the irradiated matrix a set of new bands, of low intensity, appeared that were absent in the spectrum of the as-deposited matrix. This ob-

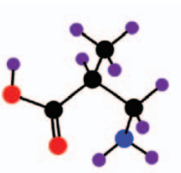

$\mathrm{D}_{1}$

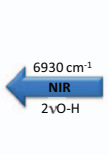

B

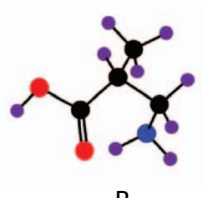

$\mathrm{B}_{1}$

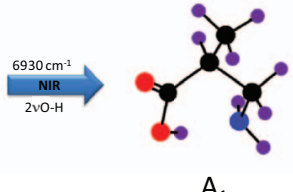

$A_{1}$
FIG. 6. Schematic representation of the observed near-IR induced conformational isomerizations of BAIBA isolated in a $\mathrm{N}_{2}$ matrix upon irradiation at $6930 \mathrm{~cm}^{-1}$. 

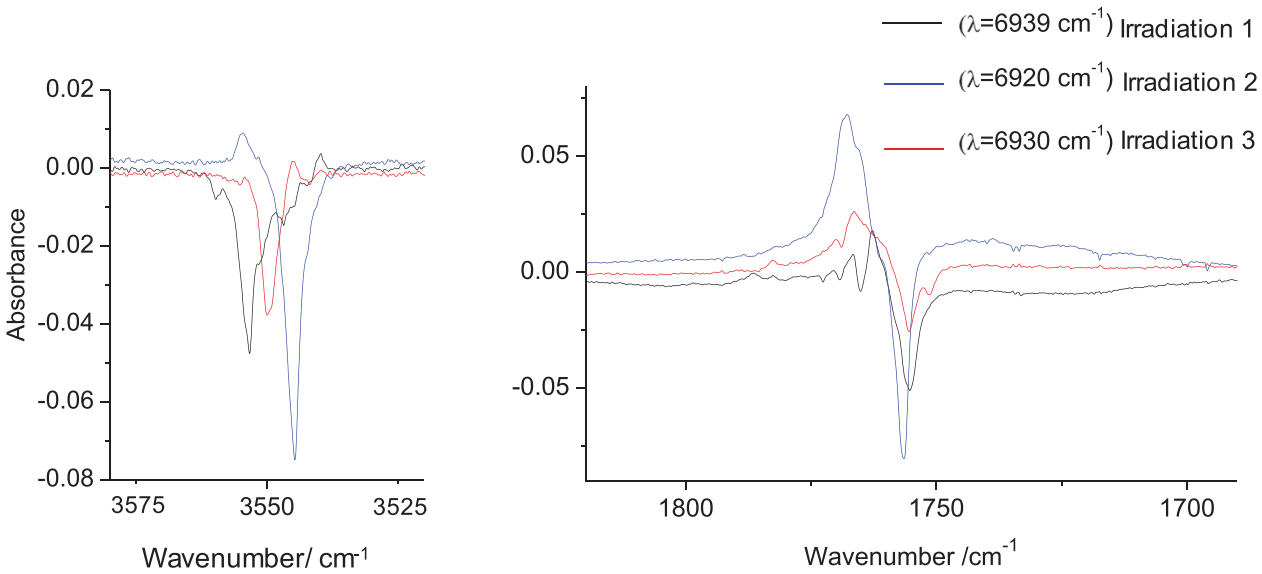

FIG. 7. Difference spectra of BAIBA monomers isolated in $\mathrm{N}_{2}$ matrix at $13 \mathrm{~K}$, in the $\mathbf{B}_{1} \nu \mathrm{O}-\mathrm{H}$ (left) and $\nu \mathrm{C}=\mathrm{O}$ (right) stretching regions. The spectra shown correspond to consecutive irradiations. Profile in black is obtained after subtracting spectrum of the freshly deposited matrix from that obtained after irradiation $1\left(\lambda=6939 \mathrm{~cm}^{-1}\right)$; profile in blue is the result of subtraction of the spectrum in black from the one obtained after irradiation $2\left(\lambda=6920 \mathrm{~cm}^{-1}\right)$; and the one in red is obtained after subtracting the blue spectrum from the one obtained as a result of irradiation $3\left(\lambda=6930 \mathrm{~cm}^{-1}\right)$.

servation indicates the production, upon pumping of the $\mathbf{B}_{\mathbf{1}}$ conformer, of a new conformer. The most characteristic new bands appear at $\sim 3600,1790-1780$, and ca. $1250 \mathrm{~cm}^{-1}$. All these bands fit well the expected vibrational signature for a trans carboxylic group not involved in a $\mathrm{O}-\mathrm{H} \cdots \mathrm{N}$ hydrogen bond, corresponding respectively to the $\nu \mathrm{O}-\mathrm{H}, \nu \mathrm{C}=\mathrm{O}$ and the higher frequency $\nu \mathrm{C}-\mathrm{O} / \delta \mathrm{COH}$ modes (the lower frequency $\nu \mathrm{C}-\mathrm{O} / \delta \mathrm{COH}$ mixed mode is expected for a trans carboxylic group around $\left.1105 \mathrm{~cm}^{-1}\right) \cdot{ }^{43,69}$ It can then be proposed that, though most of the $\mathbf{B}_{1}$ molecules convert to the $\mathbf{A}_{1}$ form upon excitation of its first $\nu \mathrm{O}-\mathrm{H}$ overtone by simultaneous rotation around the $\mathrm{C}-\mathrm{O}$ and $\mathrm{C}-\mathrm{C}_{\alpha}$ bonds, some of them undergo only internal rotation about the $\mathrm{C}-\mathrm{O}$ bond, producing the highenergy conformer $\mathbf{D}_{\mathbf{1}}$ (as represented in Figure 6), whose predicted infrared spectrum fits well the observed new bands appearing upon near-IR irradiation (see Figure 5). Note that the calculated relative energy of $\mathbf{D}_{1}$ amounts to $\Delta \mathrm{E}^{\circ}=23.8 \mathrm{~kJ}$ $\mathrm{mol}^{-1}$, which justifies the relative small amount of this form detected in the irradiated matrix (either by its comparatively inefficient production - higher barrier than for the simultaneous internal rotation around the $\mathrm{C}-\mathrm{O}$ and $\mathrm{C}-\mathrm{C}_{\alpha}$ bonds leading to formation of $\mathbf{A}_{\mathbf{1}}$-or resulting from its fast relaxation to $\mathbf{A}_{\mathbf{1}}$ ).

Another interesting observation was that the conversion of $\mathbf{B}_{\mathbf{1}}$ into $\mathbf{A}_{\mathbf{1}}$ (and, presumably also to $\mathbf{D}_{\mathbf{1}}$ ) was found to be site selective. In fact, as shown in Figure 7, irradiation at a band-site-component in the $\mathbf{B}_{1} v \mathrm{O}-\mathrm{H}$ overtone region depopulates only the fraction of molecules of $\mathbf{B}_{\mathbf{1}}$ giving rise to a specific band-site-component in other spectral regions (e.g., the $\nu \mathrm{O}-\mathrm{H}$ or $\nu \mathrm{C}=\mathrm{O}$ fundamental regions). Such selectivity of the conformational conversions resulting from near-IR excitation of matrix-isolated molecules has already been observed previously, for instance in formic and acetic acids. ${ }^{43,69}$

\section{CONCLUSIONS}

The molecular shape of BAIBA has been investigated for the first time in isolation conditions: in the gas phase and trapped into a cryogenic matrix. Four different conformers of this amino acid, corresponding to two type A $(\mathrm{OH} \cdots \mathrm{N})$ forms

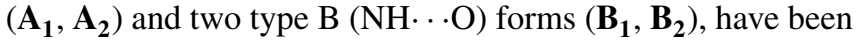
observed in the gas phase using Fourier transform microwave techniques. Unambiguous identification of the conformers has been possible by comparing the accurate experimental rotational and nuclear quadrupole constants with those predicted in vacuo. These results detail the success of the CP-FTMW combined with LA-MB-FTMW technique in the study of solid compounds and unraveling conformational species even when they present small structural changes.

Matrix isolation of the compound allowed identifying the vibrational signatures of $\mathbf{B}_{\mathbf{1}}$ and $\mathbf{A}_{\mathbf{1}} / \mathbf{A}_{\mathbf{2}}$ as well. Narrowband selective near-IR pumping of conformer $\mathbf{B}_{\mathbf{1}}$, through vibrational excitation of its $\mathrm{O}-\mathrm{H}$ stretching 1 st overtone $\left(\sim 6930 \mathrm{~cm}^{-1}\right)$ allowed to selectively convert this form into conformer $\mathbf{A}_{1}$ as well as into a new conformer of high energy $\left(\mathbf{D}_{1}\right)$ bearing an $\mathrm{NH} \cdots \mathrm{O}=\mathrm{C}$ bond and a $\mathrm{O}-\mathrm{H}$ "free" trans carboxylic group.

The relative abundances of the experimentally observed conformers, both in the jet and isolated in the matrix were explained by taken into account conformational cooling effects due to collisional relaxation, in the first case, or due to excess energy dissipation upon the landing of the molecules onto the cooled matrix substrate, in the second. These effects led to selective relaxation of the conformationally more flexible higher energy $\mathbf{B}$ and $\mathbf{C}$ conformers to the most stable form(s) belonging these groups $\left(\mathbf{B}_{1}, \mathbf{B}_{2}\right.$, in the case of the microwave experiments; presumably only $\mathbf{B}_{\mathbf{1}}$ in the case of the matrix isolation experiments).

Interpretation of the experimental results was supported by an extensive series of theoretical calculations of the potential energy landscape and conformers' relevant properties performed at both DFT(B3LYP) and MP2 levels of theory with the extended triple- $\zeta$ split-valence $6-311++\mathrm{G}(\mathrm{d}, \mathrm{p})$ basis set.

\section{ACKNOWLEDGMENTS}

These studies were performed under projects PTDC/QUI-QUI/111879/2009 (also funded by COMPETEQREN-EU) and the Portugal-Spain Bilateral Project E-7 
CRUP-MCI 2011-E03. This work has also been supported by the Ministerio de Ciencia y Innovación (Grant Nos. CTQ 2006-05981/BQU and CTQ 2010-19008), Consolider Ingenio 2010 (Grant No. CSD 2009-00038), Junta de Castilla y León (Grant No. VA070A08), and the Spain-Portugal Bilateral Project AIB2010PT-00315.

${ }^{1}$ H. R. Crumpler, C. E. Dent, H. Harris, and R. G. Westall, Nature (London) 167, 307-308 (1951).

${ }^{2}$ K. Begriche, J. Massart, A. Abbey-Toby, A. Igoudjil, P. Lettéron, and B. Fromenty, Obesity 16, 2053-2067 (2008).

${ }^{3}$ K. Begriche, J. Massart, and B. Fromenty, Fundam. Clin. Pharmacol. 24, 269-282 (2010).

${ }^{4}$ V. Schmieden and H. Betz, Mol. Pharmacol. 48, 919-927 (1995).

${ }^{5}$ S. Blanco, A. Lesarri, J. C. López, and J. L. Alonso, J. Am. Chem. Soc. 126, 11675-11683 (2004)

${ }^{6}$ M. E. Sanz, S. Blanco, J. C. López, and J. L. Alonso, Angew. Chem. 120, 6312-6316 (2008)

${ }^{7}$ S. Blanco, M. E. Sanz, J. C. López, and J. L. Alonso, Proc. Natl. Acad. Sci. U.S.A. 104, 20183-20188 (2007).

${ }^{8}$ C. Cabezas, M. Varela, I. Peña, S. Mata, J. C. López, and J. L. Alonso, Chem. Commun. 48, 5934 (2012).

${ }^{9}$ I. Peña, M. E. Sanz, J. C. López, and J. L. Alonso, J. Am. Chem. Soc. 134, 2305-2312 (2012).

${ }^{10}$ C. Pérez, S. Mata, S. Blanco, J. C. López, and J. L. Alonso, J. Phys. Chem. A 115, 9653-9657 (2011).

${ }^{11}$ M. E. Sanz, J. C. López, and J. L. Alonso, Phys. Chem. Chem. Phys. 12, 3573-3578 (2010)

${ }^{12} \mathrm{~S}$. Mata, V. Vaquero, C. Cabezas, I. Peña, C. Pérez, J. C. López, and J. L. Alonso, Phys. Chem. Chem. Phys. 11, 4141-4144 (2009).

${ }^{13}$ C. Cabezas, M. Varela, V. Cortijo, A. I. Jiménez, I. Peña, A. M. Daly, J. C. López, C. Cativiela, and J. L. Alonso, Phys. Chem. Chem. Phys. 15, 2580-2585 (2013).

${ }^{14}$ J. C. López, I. Peña, M. E. Sanz, and J. L. Alonso, J. Chem. Phys. 126, 191103 (2007)

${ }^{15}$ V. Vaquero, M. E. Sanz, J. C. López, and J. L. Alonso, J. Phys. Chem. A 111, 3443-3445 (2007)

${ }^{16}$ J. L. Alonso, I. Peña, J. C. López, and V. Vaquero, Angew. Chem., Int. Ed. 48, 1-4 (2009)

${ }^{17}$ S. Blanco, J. C. López, S. Mata, and J. L. Alonso, Angew. Chem., Int. Ed. 49, 9187-9192 (2010).

${ }^{18}$ J. L. Alonso, M. E. Sanz, J. C. López, and V. Cortijo, J. Am. Chem. Soc. 131, 4320-4326 (2009).

${ }^{19}$ J. L. Alonso, V. Cortijo, S. Mata, C. Pérez, C. Cabezas, J. C. López, and W. Caminati, J. Mol. Spectrosc. 269, 41-48 (2011).

${ }^{20}$ C. Cabezas, M. Varela, I. Peña, S. Mata, J. C. López, and J. L. Alonso, Phys. Chem. Chem. Phys. 14, 13618-13623 (2012).

${ }^{21}$ C. Cabezas, J. L. Alonso, J. C. López, and S. Mata, Angew. Chem., Int. Ed. 51, 1375-1378 (2012).

${ }^{22}$ R. Sanchez, W. Caminati, J. C. López, and J. L. Alonso, Chem. Phys. Lett. 414, 226-229 (2005).

${ }^{23}$ G. G. Brown, B. C. Dian, K. O. Douglass, S. M. Geyer, and B. H. Pate, J. Mol. Spectrosc. 238, 200-212 (2006).

${ }^{24}$ G. G. Brown, B. C. Dian, K. O. Douglass, S. M. Geyer, S. T. Shipman, and B. H. Pate, Rev. Sci. Instrum. 79, 053103 (2008).

${ }^{25}$ S. Mata, I. Peña, C. Cabezas, J. C. López, and J. L. Alonso, J. Mol. Spectrosc. 280, 91-96 (2012)

${ }^{26}$ I. Peña, A. M. Daly, C. Cabezas, S. Mata, C. Bermúdez, A. Niño, J. C. López, J.-U. Grabow, and J. L. Alonso, J. Phys. Chem. Lett. 4, 65-69 (2013).

${ }^{27}$ C. Bermúdez, I. Peña, C. Cabezas, A. M. Daly, and J. L. Alonso, ChemPhysChem 14, 893-895 (2013).

${ }^{28}$ K. M. Marzec, I. Reva, R. Fausto, and L. M. Proniewicz, J. Phys. Chem. A 115, 4342-4353 (2011)

${ }^{29}$ N. Kuş, I. Reva, and R. Fausto, J. Phys. Chem. A 114, 12427-12436 (2010).

${ }^{30}$ N. Kuş, A. Sharma, I. D. Reva, L. Lapinski, and R. Fausto, J. Phys. Chem. A 114, 7716-7724 (2010).

${ }^{31}$ S. Lopes, C. M. Nunes, A. Gómez-Zavaglia, T. M. V. D. Pinho e Melo, and R. Fausto, J. Phys. Chem. A 114, 9074-9082 (2010).

${ }^{32}$ N. Kuş, S. H. Bayari, and R. Fausto, Tetrahedron 65, 9719-9727 (2009).
${ }^{33}$ A. Sharma, I. Reva, and R. Fausto, J. Am. Chem. Soc. 131, 8752-8753 (2009).

${ }^{34}$ R. Fausto, L. Khriachtchev, and P. Hamm, "Conformational changes in cryogenic matrices," in Physics and Chemistry at Low Temperatures, edited by L. Khriachtchev (World Scientific, 2010), Chap. 3, pp. 51-84.

${ }^{35}$ A. Borba, A. Gómez-Zavaglia, and R. Fausto, J. Mol. Struct. 794, 196-203 (2006).

${ }^{36}$ I. D. Reva, A. J. Lopes Jesus, M. T. S. Rosado, R. Fausto, M. E. Eusébio, and J. S. Redinha, Phys. Chem. Chem. Phys. 8, 5339-5349 (2006).

${ }^{37}$ M. T. S. Rosado, A. J. Lopes Jesus, I. D. Reva, R. Fausto, and J. S. Redinha, J. Phys. Chem. A 113, 7499-7507 (2009).

${ }^{38}$ I. D. Reva, M. J. Nowak, L. Lapinski, and R. Fausto, J. Chem. Phys. 136, 064511 (2012).

${ }^{39}$ L. Lapinski, I. Reva, M. J. Nowak, and R. Fausto, Phys. Chem. Chem. Phys. 13, 9676-9684 (2011).

${ }^{40}$ I. D. Reva and R. Fausto, Chem. Phys. Lett. 456, 127-134 (2008).

${ }^{41}$ E. M. S. Maçôas, L. Khriachtchev, M. Pettersson, R. Fausto, and M. Räsänen, J. Phys. Chem. A 109, 3617-3625 (2005).

${ }^{42}$ E. M. S. Maçôas, L. Kriachtchev, M. Pettersson, R. Fausto, and M. Räsänen, J. Chem. Phys. 121, 1331-1338 (2004).

${ }^{43}$ E. M. S. Maçôas, L. Kriachtchev, M. Pettersson, R. Fausto, and M. Räsänen, J. Am. Chem. Soc. 125, 16188-16189 (2003).

${ }^{44}$ A. Lesarri, S. Mata, J. C. López, and J. L. Alonso, Rev. Sci. Instrum. 74, 4799-4804 (2003).

${ }^{45}$ M. J. S. Dewar, E. G. Zoebisch, E. F. Healy, and J. P. Stewart, J. Am. Chem. Soc. 107, 3902-3909 (1985).

${ }^{46}$ A. D. Becke, J. Chem. Phys. 98, 5648-5652 (1993).

${ }^{47}$ C. T. Lee, W. T. Yang, and R. G. Parr, Phys. Rev. B 37, 785-789 (1988).

${ }^{48}$ S. H. Vosko, L. Wilk, and M. Nusair, Can. J. Phys. 58, 1200-1211 (1980).

${ }^{49}$ C. Moller and M. S. Plesset, Phys. Rev. 46, 618-622 (1934).

${ }^{50}$ M. J. Frisch, M. Head-Gordon, and J. A. Pople, Chem. Phys. Lett. 166, 281-289 (1990).

${ }^{51}$ M. J. Frisch, G. W. Trucks, H. B. Schlegel et al., Gaussian 03, Revision C.02, Gaussian, Inc., Wallingford, CT, 2004.

${ }^{52}$ J. J. C. Teixeira-Dias and R. Fausto, J. Mol. Struct. 144, 199-213 (1986).

${ }^{53}$ J. J. C. Teixeira-Dias and R. Fausto, J. Mol. Struct.: THEOCHEM 282, 123-129 (1993)

${ }^{54}$ R. Fausto and E. M. S. Maçoas, J. Mol. Struct. 563-564, 27-40 (2001).

${ }^{55}$ S. Jarmelo and R. Fausto, J. Mol. Struct. 786, 175-181 (2006).

${ }^{56}$ A. Kaczor, I. D. Reva, L. M. Proniewicz, and R. Fausto, J. Phys. Chem. A 110, 2360-2370 (2006).

${ }^{57}$ A. Kaczor, I. D. Reva, L. M. Proniewicz, and R. Fausto, J. Phys. Chem. A 111, 2957-2965 (2007).

${ }^{58}$ S. G. Stepanian, A. Yu. Ivanov, D. A. Smyrnova, and L. Adamowicz, J. Mol. Struct. 1025, 6-19 (2012).

${ }^{59}$ P. Godfrey, R. D. Brown, and F. M. Rodgers, J. Mol. Struct. 376, 65-81 (1996).

${ }^{60}$ R. Fausto, J. Mol. Struct.: THEOCHEM 315, 123-136 (1994).

${ }^{61}$ See supplementary material at http://dx.doi.org/10.1063/1.4799456 for Table S-I, with the MP2 calculated rotational constants, dipole moment components and ${ }^{14} \mathrm{~N}$ quadrupole coupling constants for the 19 most stable conformers of BAIBA, Tables S-II to S-V with the observed frequencies and residuals for the rotational transitions of conformers $\mathbf{A}_{1}, \mathbf{A}_{2}, \mathbf{B}_{1}$ and $\mathbf{B}_{\mathbf{2}}$, and Table S-VI, with the proposed assignments for the IR spectrum of BAIBA isolated in a $\mathrm{N}_{2}$ matrix.

${ }^{62}$ D. F. Plusquellic, jb95 - Spectral fitting program, NIST, Gaithersburg, MD, 2009, see http://physics.nist.gov/jb95.

${ }^{63}$ J. K. G. Watson, Vibrational Spectra and Structure (Elsevier, Amsterdam, 1977), Vol. 6, pp. 1-89.

${ }^{64}$ W. Gordy and R. L. Cook, Microwave Molecular Spectra (Wiley, New York, 1984).

${ }^{65}$ G. T. Fraser, R. D. Suenram, and C. L. Lugez, J. Phys. Chem. A 104, 11411146 (2000).

${ }^{66}$ R. S. Ruoff, T. D. Klots, T. Emilsson, and H. S. Gutowsky, J. Chem. Phys. 93, 3142-3150 (1990)

${ }^{67}$ P. D. Godfrey and R. D. Brown, J. Am. Chem. Soc. 120, 10724-10732 (1998).

${ }^{68}$ G. M. Florio, R. A. Christie, K. D. Jordan, and T. S. Zwier, J. Am. Chem. Soc. 124, 10236-10247 (2002).

${ }^{69}$ E. M. S. Maçôas, J. Lundell, M. Pettersson, L. Kriachtchev, R. Fausto, and M. Räsänen, J. Mol. Spectrosc. 219, 70-80 (2003). 